\title{
Leitura argumentativa de proposta de redação do Enem e critérios para definição de fuga $e$ tangenciamento de tema
}

\author{
Telisa Furlanetto Graeff \\ Lauro Gomes*
}

\section{Resumo}

Este trabalho propõe uma leitura integrada dos textos que constituem a proposta de redação do Enem 2011, que explicita a relação entre as ideias centrais de cada texto, para chegar à ideia central da proposta. A partir disso, busca-se estabelecer os limites de entendimento, tangenciamento e fuga da ideia central da proposta de redação. Esse procedimento de leitura utiliza princípios e conceitos da Teoria dos Blocos Semânticos - versão atual da Teoria da Argumentação na Língua - desenvolvida por Oswald Ducrot e Marion Carel na Escola de Altos Estudos em Ciências Sociais de Paris. Pretende-se, com este trabalho, fornecer subsídios teórico-metodológicos capazes de qualificar as práticas de ensino de leitura e produção de textos dissertativo-argumentativos, e os critérios utilizados na avaliação de desempenhos em leitura.

Palavras-chave: Leitura. Proposta de redação. Ensino. Bloco semântico.

\section{Considerações iniciais ${ }^{1}$}

Cada vez mais a educação tem sido reconhecida como um dos setores mais importantes para o desenvolvimento sustentável de um país. Com isso, tem-se verificado, no Brasil, grande interesse do Ministério da Educação (MEC) em expandir e regular eficientemente a qualidade da educação básica e da superior. Por meio de avaliações externas, como Sistema Nacional de Avaliação da Educação Básica, Prova Brasil, Exame Nacional do Ensino Médio (Enem) e Exame Nacional de Desempenho de

Doutora em Linguística Aplicada pela PUCRS. Pós-doutora pelo Centre de Recherches sur les Arts et le Langage, da École des Hautes Études en Sciences Sociales, Paris. Docente do Programa de Pós-Graduação em Letras da Universidade de Passo Fundo. E-mail: telisagraeff@yahoo.com.br

** Mestre em Letras. Doutorando em Letras pela Universidade de Passo Fundo (bolsista Prosup/Capes). Professor de Leitura e Produção Textual do Colégio Franciscano São José de Erechim. E-mail: lauro.20@bol.com.br

Data de submissão: set. 2015 - Data de aceite: nov. 2015 http://dx.doi.org/10.5335/rdes.v11i2.5505 
Estudantes (Enade), verifica-se que o MEC visa não apenas a regular aprendizagens e apontar índices sobre o nível de letramento dos estudantes, mas também a assegurar justiça, igualdade para todos. Desse modo, avaliar tem sido uma atividade desafiadora para os docentes de língua portuguesa, tanto em se tratando de contextos de avaliações em larga escala, como o Enem, quanto em processos de seleção para ingresso no ensino superior, como vestibulares, em que, a cada nova edição, aumenta $o$ número de participantes e a objetividade precisa ser assegurada no julgamento dos desempenhos em todas as competências avaliadas nas redações.

É importante salientar que o desafio se intensifica nos referidos testes, pois, como a avaliação das produções deve ser feita por mais de um avaliador, as discrepâncias entre as notas atribuídas por um e por outro, nos critérios que envolvem maior grau de subjetividade - como os que examinam o desempenho do participante na leitura da proposta de redação ${ }^{2}$ - atrasam o processo e prejudicam-no em diversos aspectos. Em 2013, o Instituto Nacional de Estudos e Pesquisas Educacionais Anísio Teixeira (Inep), responsável por subsidiar a formulação de políticas na área de educação, mediante a elaboração de diagnósticos e recomendações decorrentes da avaliação da educação básica e da superior, na busca de aumentar a objetividade na avaliação da redação do Enem, conforme o Guia do participante, passou a considerar
[...] discrepância a divergência de notas atribuídas pelos avaliadores, quando: elas diferirem, no total, por mais de 100 (cem) pontos ou a diferença for superior a 80 (oitenta) pontos em qualquer uma das competências (INEP, 2013, p. 8).

No entanto, uma decisão dessa natureza, apesar de representar um avanço significativo rumo à credibilidade plena do Enem pelas universidades brasileiras, requer objetividade até mesmo no julgamento de competências linguístico-discursivas destinadas a examinar o entendimento da ideia central da proposta de redação. Destaque-se que, a propósito do estabelecimento de critérios para a avaliação de redações, Costa Val comenta que os critérios utilizados em seu trabalho para o "julgamento das redações são, inegavelmente, fluidos e subjetivos" (2006, p. 34). Afirma, ainda, que não há como fugir da subjetividade nesse processo. Entretanto, pode-se constatar que, em processos seletivos e em avaliações em larga escala, a objetividade ${ }^{3}$ faz-se essencial em todos os critérios, não só para agilizar o processo, mas também, e sobretudo, para assegurar um tratamento justo, igual para todos.

Em vista disso, este trabalho propõe uma leitura integrada dos textos que constituem a proposta de redação do Enem 2011 e explicita a relação entre as ideias centrais de cada texto, para chegar à ideia central da proposta. A partir disso, busca-se estabelecer os limites de entendimento, tangenciamento e fuga da ideia central da proposta de redação, 
cujas noções são essenciais a qualquer avaliação de desempenhos em leitura. Para tanto, apresentam-se, na próxima seção, os princípios e conceitos da teoria dos blocos semânticos, para, em seguida, explicitarem-se a metodologia e a análise do corpus. Por fim, apresentam-se as contribuições deste trabalho para a área de letras e linguística nas considerações finais.

\section{Apresentando a teoria dos blocos semânticos}

Criada com a tese de doutorado de Marion Carel (1992), a Teoria dos Blocos Semânticos (TBS) - considerada como uma terceira fase da teoria da Argumentação na Língua - defende que o sentido de uma entidade linguística constitui-se por certos discursos que dela se podem evocar. Esses discursos, denominados por Carel e Ducrot (2005) de encadeamentos argumentativos, constituem intralinguisticamente $o$ sentido e manifestam-se sob a fórmula X CONECTOR Y. Todavia, enquanto nas fases anteriores à TBS considerava-se haver apenas o conector donc (portanto) - que constituía os encadeamentos argumentativos normativos -, Carel (1995) também considerou a existência do conector pourtant (mesmo assim), que constitui os encadeamentos argumentativos transgressivos, antes considerados uma anomalia por transgredirem normas da comunidade linguística.
Salienta Carel que esta teoria considera como encadeamentos argumentativos as sequências de duas proposições gramaticais ligadas não apenas por conectores do tipo de portanto (como se...então e porque), mas também as sequências de duas proposições gramaticais ligadas por conectores do tipo de mesmo assim, (mesmo se, ou ainda apesar de que) (2013, p. 257). Por conseguinte, a TBS é uma teoria do encadeamento argumentativo, que se estende por toda a língua, inclusive porque, conforme destaca Carel (2013), os encadeamentos argumentativos estão na base de todas as construções semânticas.

Quando Carel e Ducrot (2005) explicam o porquê de seu interesse pelos dois tipos de encadeamentos argumentativos, os normativos e os transgressivos, eles destacam que é nesses dois tipos de concatenação que cada um dos segmentos encadeados ganha sentido. Postulam os referidos linguistas que é da interdependência semântica, isto é, da relação que um segmento mantém com o outro no encadeamento que surge o sentido. Assim sendo, em (1) Há um verdadeiro problema, portanto o deixemos de lado, o segmento X: há um verdadeiro problema só recebe seu sentido pela continuação $\mathrm{Y}$ : portanto o deixemos de lado, e o segmento Y: portanto o deixemos de lado somente adquire sentido em relação com X.

Ressalte-se, porém, que um discurso normativo do tipo A DC B - como o que é explicitado por (1) - não tem nenhuma 
relação com o que habitualmente se chama de "raciocínio". Isso deriva do fato de que, em discursos dessa natureza, recorrentes nas línguas naturais, o que se diz no primeiro segmento, isto é, no predicado $A$ somente passa a ter sentido quando determinado por aquilo que se diz no segundo segmento, isto é, no predicado $B$. Considerando-se um encadeamento argumentativo X CON $\mathrm{Y}$, pode-se denominar A o segmento $\mathrm{X}$ e B, o segmento Y. Tomando-se como exemplo o encadeamento (2) O hotel está perto da Universidade, portanto é fácil chegar, Carel e Ducrot chamam A para perto e B para fácil chegar (2005, p. 20).

Admitida essa convenção, os referidos autores definiram a noção de aspecto argumentativo e, para tanto, convencionaram chamar A DC B de aspecto, visto que representa um conjunto de encadeamentos argumentativos normativos X DC Y. Notaram, dessa forma, que um aspecto A DC B contém, entre outros, encadeamentos como (2) O hotel está perto da Universidade, portanto é fácil chegar., (3) A Catedral está perto da Faculdade, portanto é fácil chegar. e (4) Meu dormitório está perto do teu, portanto é fácil chegar., uma vez que, em todos os casos, o pertinente é A, perto, e $\mathrm{B}$, fácil chegar.

Feitos esses esclarecimentos, cumpre destacar que é exatamente da chamada interdependência semântica que se estabelece entre os dois predicados de um encadeamento argumentativo que se origina o bloco semântico. Desse modo, segundo esclarecem Carel e Ducrot, um bloco semântico pode ser definido como uma entidade semântica, unitária e indecomponível, expressa nos encadeamentos argumentativos. A título de exemplificação, tomem-se os discursos (1) e (1'), explicitados pelos referidos linguistas, a fim de mostrar que a interdependência semântica que se estabelece entre A e B é a mesma nos dois casos. Observem-se os dois discursos: (1) Há um verdadeiro problema, portanto o deixemos de lado. e (1') Há um verdadeiro problema, mesmo assim não o deixemos de lado.

Notadamente, em ambos os encadeamentos, o pertinente é A, problema, e $\mathrm{B}$, deixar de lado, e a interdependência semântica entre A e B é a mesma. Logo, o bloco semântico que esses discursos imprimem relaciona dificuldade/postergar. Além disso, saliente-se que essa concatenação de A e B permite construir oito aspectos argumentativos, organizados em dois blocos de quatro aspectos cada um. Veja-se, no quadrado argumentativo a seguir, que o bloco semântico (1) relaciona quatro aspectos: 
Figura 1-BS1: relaciona dificuldade e postergar

(1) DIFICULDADE PT NEG-POSTERGAR

(1) A PT NEG-B

(3) NEG-DIFICULDADE DC NEG-

POSTERGAR

(3) NEG-A DC NEG- B
(2) NEG-DIFICULDADE PT POSTERGAR

(2) NEG-A PT B

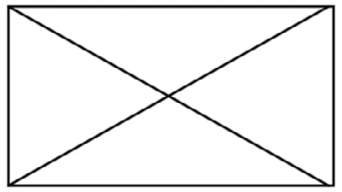

(4) DIFICULDADE DC POSTERGAR

(4) A DC B

Figura 2 - BS2: relaciona dificuldade e não postergar

(1) DIFICULDADE PT POSTERGAR

(1) A PT B

(3)NEG- DIFICULDADE DC POSTERGAR (3)NEG- A DC B
(2) NEG-DIFICULDADE PT NEG-POSTERGAR

(2) NEG-A PT NEG-B

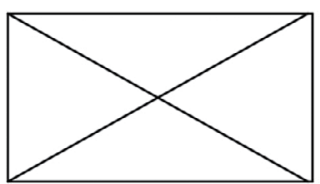

(4) DIFICULDADE DC NEG-POSTERGAR (4) A DC NEG- B

Fonte: figura fundamentada em Carel e Ducrot (2005).

Convém destacar, diante disso, que Carel e Ducrot (2005) esclarecem ser totalmente diferente essa relação estabelecida num encadeamento argumentativo da ligação de duas informações, o que significa dizer que a TBS se mantém fiel à proposta saussuriana de descrever a língua a partir dela mesma, sem fazer intervir o mundo nem o pensamento. Entre outros objetivos, a TBS busca dar as regras da linguagem cotidiana a partir do emprego dos conectores DC e PT.

São também conceitos essenciais aos propósitos deste trabalho os de argumentação interna (AI) e de argumentação externa (AE). A fim de explicitá-los, convém destacar, segundo Carel (2012), que a TBS distingue duas maneiras de ligações entre um termo e os aspectos argumentativos que ele significa. Isso revela que essa distinção - que, segundo a autora, está relacionada ao estudo argumentativo das "frases sintáticas" - deve ocorrer em virtude de que o vínculo existente entre os enunciados e as entidades semânticas tanto pode ser interno como externo. Conforme o esclarecimento feito por Carel (2012, p. 39, grifo do autor, tradução nossa), uma frase como:

(5) Até mesmo Pedro, que é muito solitário, veio à inauguração. (même Pierre, qui est très solitaire, est venu à l'inauguration), 
pode ser estudada argumentativamente de duas maneiras. A primeira, que se interessa nas argumentações desenvolvidas no interior da própria frase, é capaz de explicitar que (6) Pedro é muito solitário mesmo assim veio à inauguração (Pierre est très solitaire pourtant il est venu à l'inauguration) revela a argumentação interna (AI) de (5). E a segunda, que se interessa pelas argumentações às quais a frase (5) pode integrar-se, é capaz de explicitar que (7) Até mesmo Pedro, que é muito solitário, veio à inauguração, portanto o diretor está contente (même Pierre, qui est très solitaire, est venu à l'inauguration donc le directeur est content) revela a argumentação externa (AE) de (5).

Diante disso, conforme esclarecem Carel e Ducrot, a argumentação externa de uma entidade linguística é constituída pelos encadeamentos argumentativos que chegam à entidade (AE à esquerda) ou que partem dela (AE à direita) (2005, p. 65). Partindo da palavra prudente, por exemplo, encontram-se encadeamentos como (8) Pedro é prudente, portanto não se envolverá em acidentes e (9) Pedro é prudente, portanto viajará com segurança. Ademais, encontram-se, formando a $\mathrm{AE}$ à esquerda de prudente, encadeamentos que chegam até prudente, como é o caso de (10) Tem medo de morrer, portanto é prudente.

É preciso observar, em vista disso, que uma propriedade da $\mathrm{AE}$ é o fato de a própria entidade linguística fazer parte dos encadeamentos externos que a des- crevem. Nos exemplos citados, a palavra prudente faz parte dos encadeamentos que a descrevem. Outra característica importante dessa argumentação é o fato de os aspectos pertencentes à $\mathrm{AE}$ existirem sempre em pares. Em outras palavras, se houver na AE de uma entidade o aspecto PRUDENTE DC SEGURANÇA, por exemplo, haverá também PRUDENTE PT NEG-SEGURANÇA, uma vez que, segundo Carel e Ducrot (2005), cada aspecto em DC está associado a um aspecto em PT mais NEG.

Explicitadas essas duas características da $\mathrm{AE}$, saliente-se que essa argumentação também pode ser estrutural e contextual, classificações muitas vezes necessárias a determinadas análises discursivas. Classifica-se como estrutural a $\mathrm{AE}$ que faz parte da significação linguística da entidade, isto é, que está prevista pela língua, como é o caso de PRUDENTE DC SEGURANÇA e de PRUDENTE PT NEG-SEGURANÇA, cujos aspectos, segundo afirmam Carel e Ducrot (2005), fazem parte da significação de prudente. Entretanto, quando é a situação discursiva que vincula a $\mathrm{AE}$ à entidade, deve-se classificar a $\mathrm{AE}$ como contextual, como é o caso dos aspectos PRUDENTE DC MERECE CONFIANÇA, PRUDENTE PT NEG-MERECE CONFIANÇA, referidos a um motorista, e, da mesma forma, PRUDENTE DC NEG-MERECE CONFIANÇA e PRUDENTE PT MERECE CONFIANÇA, no caso de se tratar de um guarda-costas. São, portanto, AEs estruturais aquelas 
que estão estritamente determinadas pela língua e, contextuais, aquelas que dependem da situação discursiva.

Do mesmo modo, revisando-se detalhadamente o vínculo interno que existe entre enunciados e entidades semânticas, a primeira característica da argumentação interna a ser realçada é que a AI de uma entidade $e$, conforme palavras de Carel e Ducrot: "[...] está constituída por um certo número de aspectos aos quais pertencem os encadeamentos que parafraseiam essa entidade $e "(2005$, p. 65 , grifo do autor, tradução nossa $)^{4}$. Por conseguinte, duas características básicas são explicitadas pelos referidos linguistas para diferenciar uma AI de uma AE. A primeira é que os encadeamentos que fazem parte da AI de $e$ não contêm $e$. Por exemplo, a AI de prudente é PERIGO DC PRECAUÇÃO; de temeroso, NEG-PERIGO PT PRECAUÇÃO; e de inteligente, NEG-FÁCIL PT COMPREENDE. E a segunda é que, na $\mathrm{AI}$ de uma entidade, não se encontram dois aspectos conversos, visto que a relação de conversão, conforme explicado anteriormente, diz respeito à $\mathrm{AE}$.

Vale lembrar que a relação discursiva possível de aparecer na AI de algumas palavras - como ocorre, por exemplo, nas palavras concretas exame e penei$r a$ - é a relação de reciprocidade. $\mathrm{Na}$ AI de exame, encontram-se os aspectos normativos BOM DC APROVAe, reciprocamente, NEG-BOM DC NEG-APROVA; e, na AI da palavra concreta peneira, encontram-se os aspectos normativos re- cíprocos FINO DC PASSA e NEG-FINO DC NEG-PASSA. Essa relação, suscetível de aparecer na $\mathrm{AI}$, não aparece na $\mathrm{AE}$ de entidades linguísticas. Essa é, então, outra importante diferença existente entre argumentação interna e externa.

Outra característica da AI que vai ao encontro das características da $\mathrm{AE}$ é a existência de AIs contextuais e de AIs estruturais. Segundo Carel e Ducrot (2005), estas fazem parte da significação da entidade linguística - como PERIGO DC PRECAUÇÃO, AI estrutural da entidade prudente -; e aquelas são produzidas pelo próprio discurso, como no enunciado de um anarquista que diz: Chamo "livre" a quem faz o que a sociedade proíbe, cujo sentido de livre PROIBIDO DC FAZ, é construído no próprio discurso. Logo, esse não é o sentido que livre tem na língua.

Ampliando ainda mais a noção de argumentação interna, essencial às análises discursivas realizadas neste trabalho, faz-se importante trazer também a noção de motivo argumentativo, a qual é apresentada por Carel nos seguintes termos:

[...] uma parte de texto constitui um "motivo argumentativo" se, ao mesmo tempo, ela exprime um aspecto e evoca um encadeamento, isto é, se ela comunica um julgamento completo (2012, p. 54, tradução nossa) ${ }^{5}$

Para exemplificar, observe-se a análise feita por Graeff de um trecho do livro Claude Gueux, de Victor Hugo, a propósito do esclarecimento do conceito de motivo argumentativo. Confira-se o trecho traduzido pela referida autora: 
Um inverno, o trabalho faltou. Nada de fogo nem pão no sótão. O homem, a moça e a criança passaram frio e fome. $O$ homem roubou. Eu não sei o que ele roubou, eu não sei onde ele roubou. O que eu sei, é que desse roubo resultaram três dias de pão e de fogo para a mulher e a criança, e cinco anos de prisão para o homem (2012, p. 198, grifo do autor). ${ }^{6}$

Conforme salienta Graeff, o principal encadeamento argumentativo que esse trecho permite evocar é roubou pequena quantidade mesmo assim sofreu grande punição. Segundo Graeff:

A esse encadeamento se pode associar o aspecto argumentativo PEQUENO DELITO PT GRANDE PUNIÇÃO, que pode ser a AI de injustiça. Tem-se, assim, um julgamento argumentativo completo ou um motivo argumentativo (2012, p.198-199, grifo da autora).

São também úteis à análise argumentativa de textos, as noções de conexão por contiguidade e por similaridade propostas por Graeff (2012), pois auxiliam na seleção dos encadeamentos a reter e a eliminar, durante o processo de leitura, para compreensão da ideia central do texto. Mostra a referida autora que a conexão por similaridade é produzida pelas relações entre enunciados que exprimem o mesmo aspecto argumentativo, isto é, que têm a mesma AI, resultando em mais de um julgamento argumentativo, é responsável pela reiteração, pela exemplificação, pelo esclarecimento de um ponto de vista, de um mesmo aspecto argumentativo. Já a conexão por contiguidade, produzida pelas relações entre $\mathrm{AI}$ e $\mathrm{AE}$ de uma entidade linguística, resulta num só julgamento argumentativo, sendo essa, portanto, a conexão que permite a progressão temática do texto.

\section{Análise da proposta de redação do Enem 2011}

Retomados os conceitos necessários aos propósitos deste trabalho, apresenta-se o procedimento utilizado na análise dos textos que compõem a proposta de redação do Enem 2011 - corpus de análise deste trabalho, composta de um parágrafo de instruções e de três textos ditos "motivadores".

Aos três textos foi aplicado o procedimento que segue: a) dividiu-se o texto em trechos que constituíssem um motivo argumentativo, isto é, capazes de expressar um aspecto e evocar um encadeamento; b) foram evocados os encadeamentos $\mathrm{e}$ associados os aspectos expressos nesses trechos; c) foram eliminados os trechos que reiteravam um mesmo aspecto argumentativo (enunciados conectados por similaridade) e mantidos os que faziam o tema do texto progredir (enunciados conectados por contiguidade); d) por fim, identificados o encadeamento e 0 aspecto argumentativo que expressavam a ideia central de cada texto, relacionaram-se essas ideias por meio da $\mathrm{AI}$ e da $\mathrm{AE}$ das entidades que as compõem, construindo, desse modo, a ideia central da proposta.

Antes de se fazer a análise dos textos é interessante mencionar a observação de Graeff e Gomes (2012) sobre a influência das provas do Enem no surgimento do gênero proposta de redação. Se, antes desse exame, uma proposta de redação poderia conter apenas uma instrução como escreva sobre $x$, atualmente elas 
aparecem com pelo menos um texto e um título, o que passa a exigir do candidato capacidade de leitura.

A estrutura composicional das propostas de redação do Enem está relativamente estabilizada. Sempre inicia com a apresentação e a caracterização da atividade a ser realizada, seguida de mais de um texto, como se pode verificar:

Com base na leitura dos seguintes textos motivadores e nos conhecimentos construídos ao longo de sua formação, redija texto dissertativo-argumentativo em norma culta escrita da língua portuguesa sobre o tema VIVER EM REDE NO SÉCULO XXI: OS LIMITES ENTRE O PÚBLICO E O PRIVADO, apresentando proposta de conscientização social que respeite os direitos humanos. Selecione, organize e relacione, de forma coerente e coesa, argumentos e fatos para defesa de seu ponto de vista.

Abaixo desse trecho, que fornece instruções ao estudante, relativas ao gênero em que deverá desenvolver sua redação, dissertativo-argumentativo, ao estilo de linguagem a ser utilizado no texto, a norma culta da língua portuguesa, e ao tema a ser abordado, Viver em rede no século XXI: os limites entre o público e o privado, segue o primeiro texto da proposta, intitulado Liberdade sem fio. Leia-se:

A ONU acaba de declarar o acesso à rede um direito fundamental do ser humano - assim como saúde, moradia e educação. No mundo todo, pessoas começam a abrir seus sinais privados de $w i$-fi, organizações e governos se mobilizam para expandir a rede para espaços públicos e regiões aonde ela ainda não chega, com acesso livre e gratuito (ROSA, G.; SANTOS, 2011) (fragmento).
Desse discurso evoca-se, de início, o encadeamento argumentativo normativo [A ONU declara que o acesso à rede é direito fundamental, portanto pessoas, organizações e governos se mobilizam para expandir a todos com acesso livre e gratuito] ao qual se associa o aspecto argumentativo SER DIREITO FUNDAMENTAL DC TER GARANTIA DE ACESSO LIVRE E GRATUITO, que constitui a argumentação interna de liberdade de acesso, cuja expressão está diretamente relacionada ao título do texto.

Nessa direção, o conteúdo argumentativo do texto em foco, filtrado pela subjetividade dos estudantes, poderia servir-lhes como ponto de partida de sua redação e, fundamentalmente, deveria perpassar seus projetos de texto.

Abaixo, apresenta-se o segundo texto da proposta, intitulado $A$ internet tem ouvidos e memória, cuja argumentação será analisada na sequência. Confira-se:

Uma pesquisa da consultoria Forrester Research revela que, nos Estados Unidos, a população já passou mais tempo conectada à internet do que em frente à televisão. Os hábitos estão mudando. No Brasil, as pessoas já gastam cerca de $20 \%$ de seu tempo on-line em redes sociais. A grande maioria dos internautas (72\%, de acordo com o Ibope Mídia) pretende criar, acessar e manter um perfil em rede. "Faz parte da própria socialização do indivíduo do século XXI estar numa rede social. Não estar equivale a não ter uma identidade ou um número de telefone no passado", acredita Alessandro Barbosa Lima, CEO da e.Life, empresa de monitoração e análise de mídias. 
As redes sociais são ótimas para disseminar ideias, tornar alguém popular e também arruinar reputações. Um dos maiores desafios dos usuários de internet é saber ponderar o que se publica nela. Especialistas recomendam que não se deve publicar o que não se fala em público, pois a internet é um ambiente social e, ao contrário do que se pensa, a rede não acoberta anonimato, uma vez que mesmo quem se esconde atrás de um pseudônimo pode ser rastreado e identificado. Aqueles que, por impulso, se exaltam e cometem gafes podem pagar caro. (Disponível em: <http://terra.com.br>. Acesso em: 30 jun. 2011. (adaptado).

Trecho 1: Uma pesquisa da consultoria Forrester Research revela que, nos Estados Unidos, a população já passou mais tempo conectada à internet do que em frente à televisão. Os hábitos estão mudando. No Brasil, as pessoas já gastam cerca de $20 \%$ de seu tempo on-line em redes sociais.

É importante observar que a organização semântico-argumentativa desse primeiro trecho realiza-se em torno da argumentação interna (AI) de os hábitos estão mudando, constituída pelo aspecto argumentativo FAZIA X PT NEG-FAZ MAIS, à qual, de acordo com Graeff (2012), os enunciados [Uma pesquisa da consultoria Forrester Research revela que, nos Estados Unidos, a população já passou mais tempo conectada à internet do que em frente à televisão] e [No Brasil, as pessoas já gastam cerca de $20 \%$ de seu tempo on-line em redes sociais] conectam-se pelo processo de similaridade, visto que ambos funcionam como exemplos e, portanto, reiteram a $\mathrm{AI}$ de Os hábitos estão mudando.
Trecho 2: A grande maioria dos internautas $(72 \%$, de acordo com o Ibope Mídia) pretende criar, acessar e manter um perfil em rede.

O julgamento argumentativo desse trecho é constituído pelo encadeamento argumentativo normativo [ser internauta, portanto criar, acessar e manter um perfil em rede] e pelo aspecto argumentativo nele expresso, SER INTERNAUTA DC TER IDENTIDADE NA REDE, que constitui uma AE de internauta.

Trecho 3: "Faz parte da própria socialização do indivíduo do século XXI estar numa rede social. Não estar equivale a não ter uma identidade ou um número de telefone no passado", acredita Alessandro Barbosa Lima, CEO da e.Life, empresa de monitoração e análise de mídias.

Interessante observar que esse trecho explicita um par de encadeamentos argumentativos normativos cujos aspectos do bloco semântico mantêm entre si relação de reciprocidade. $\mathrm{O}$ primeiro encadeamento, [estar numa rede social, portanto ter participação social], tem como aspecto expresso ESTAR EM REDE DC TER IDENTIDADE SOCIAL e o segundo, [não estar numa rede social, portanto não ter uma identidade ou um número de telefone no passado], possui como aspecto NEG-ESTAR EM REDE DC NEG-TER IDENTIDADE SOCIAL, recíproco do anterior.

Trecho 4: As redes sociais são ótimas para disseminar ideias, tornar alguém popular e também arruinar reputações. 
Um dos maiores desafios dos usuários de internet é saber ponderar o que se publica nela.

Desse trecho, pode-se evocar o encadeamento argumentativo [as redes sociais disseminam ideias para o bem e para o mal, portanto exigem cuidado com o que é publicado], cujo aspecto expresso é TUDO É PÚBLICO NAS REDES SOCIAIS DC PRECAUÇÃO COM O QUE SE PUBLICA, que constitui uma AI de prudência em rede. Por haver o acréscimo de uma nova $\mathrm{AI}$ no texto, note-se que a conexão existente entre os enunciados desse quarto trecho e os que constituem o terceiro trecho ocorre pelo processo de contiguidade.

Trecho 5: Especialistas recomendam que não se deve publicar o que não se fala em público, pois a internet é um ambiente social e, ao contrário do que se pensa, a rede não acoberta anonimato, uma vez que mesmo quem se esconde atrás de um pseudônimo pode ser rastreado e identificado. Aqueles que, por impulso, se exaltam e cometem gafes podem pagar caro.

Desse trecho, que constitui um argumento por autoridade, evoca-se o encadeamento argumentativo normativo [não se fala em público, portanto não se fala na rede] cujo aspecto nele expresso, NEG-DIZÍVEL EM PÚBLICO DC NEG-DIZÍVEL EM REDE, corresponde à AI de conteúdo privado. Pelo fato de esse aspecto argumentativo estar diretamente relacionado ao tema da proposta de redação, é importante observar, no quadrado argumentativo, também os outros aspectos que com ele se relacionam. Confira-se o quadrado argumentativo do bloco semântico que relaciona dizível em público a dizível em rede:

Figura 3 - BS1: relaciona dizer em público a dizer em rede

(1) DIZÍVEL EM PÚBLICO PT NEG-

DIZÍVEL EM REDE

(3) NEG-DIZÍVEL EM PÚBLICO DC NEG-DIZÍVEL EM REDE

Fonte: imagem criada pelo autor (2014).
(2) NEG-DIZÍVEL EM PÚBLICO PT DIZÍVEL EM REDE

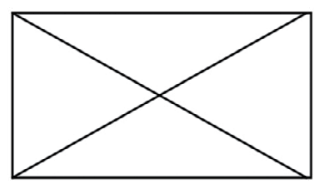

(4) DIZÍVEL EM PÚBLICO DC DIZÍVEL EM REDE
Eis que, de acordo com o conteúdo argumentativo explicitado no discurso em análise, vetava-se a possibilidade de o aluno argumentar a partir do aspecto (2), por exemplo, NEG-DIZÍVEL
EM PÚBLICO PT DIZÍVEL EM REDE, haja vista que é exatamente a realização desse aspecto que arruína a reputação de muitas pessoas no século XXI. Note-se, entretanto, a possibilidade de se 
explicitar, por meio de até, o aspecto (1), transposto de (3), DIZÍVEL EM PÚBLICO PT NEG-DIZÍVEL EM REDE. Ocuparia este último aspecto lugar em discursos argumentativamente de excelente qualidade, os quais, além de fugirem ao senso comum, demonstrariam preocupação em propor solução para o problema. Evidentemente que o fato de se tomar precaução, evitando-se dizer em rede inclusive conteúdos que se diriam em público, fora da rede, seria propor aumentar o cuidado com o que se diz em ambientes virtuais, porque, muitas vezes, o internauta pode ser mal interpretado pelos outros usuários da rede e sofrer consequências diversas por isso.

Explicitados os aspectos do bloco semântico anteriormente referido, na sequência do discurso, evoca-se o encadeamento [é ambiente social, mesmo assim não acoberta o anonimato], que, de acordo com o que propõe Graeff (2012), conecta-se por similaridade ao encadeamento seguinte, [esconder-se atrás de um pseudônimo, mesmo assim ser rastreado e identificado], uma vez que ambos têm o mesmo aspecto expresso, É AMBIENTE PÚBLICO PT SER IDENTIFICADO, que constitui a argumentação interna (AI) de inexistência de anonimato. Notadamente, esse último aspecto argumentativo relaciona a ideia de que quanto maior 0 espaço social maior o anonimato. Fala-se de anonimato em cidades grandes em contraposição à responsabilidade numa cidade pequena. A internet tem cidadãos do mundo que deveriam ser completa- mente anônimos, mas, ao contrário, não há anonimato em rede, podendo-se, por conseguinte, ter um "avatar" a qualquer momento. Por fim, o encadeamento argumentativo que esse trecho permite evocar é [exaltar-se, portanto sofrer consequências], cujo aspecto expresso, DIZER O QUE NEG-DIRIA EM PÚBLICO DC SOFRER CONSEQUÊNCIAS, constitui a AI contextual de justiça.

Diante disso, chega-se à conclusão de que a ideia central desse segundo texto, que também compreende o conteúdo argumentativo do primeiro, pode ser resumida no aspecto argumentativo único, TER GARANTIA DE ACESSO À REDE PT NEG-SER LIVRE PARA PUBLICAR O QUE QUISER, o qual está diretamente relacionado ao tema da proposta de redação. Destaque-se que ele é transgressivo, posto que expressa uma exceção de TER GARANTIA DE ACESSO À REDE DC SER LIVRE PARA PUBLICAR O QUE QUISER.

Feita a análise dos dois primeiros textos, contendo apenas linguagem verbal, confira-se o último texto da proposta, com linguagem verbal e não verbal. 
Figura 4 - Quadrinhos dos anos 10

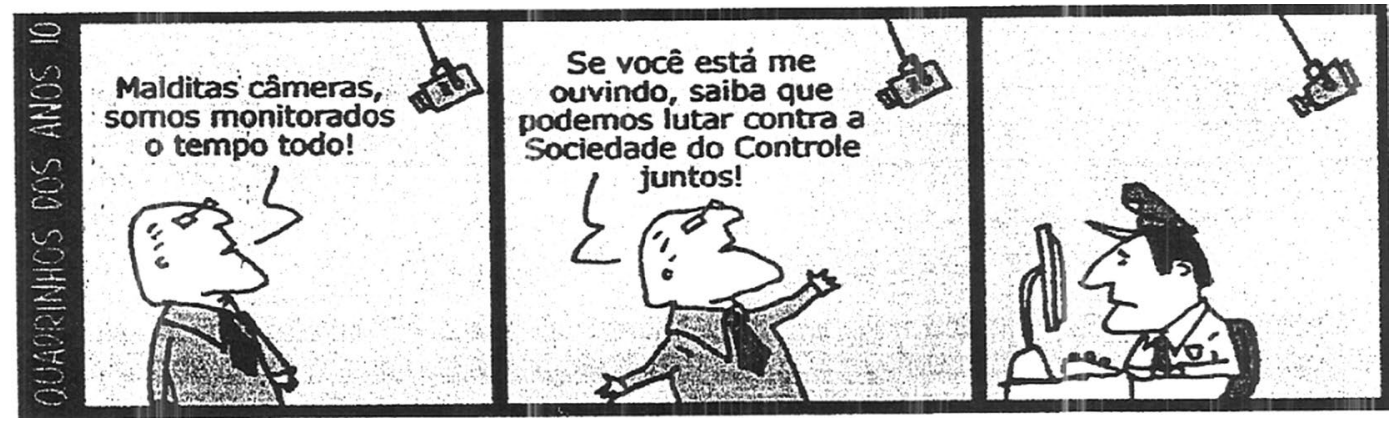

Fonte: figura retirada da proposta de redação do Enem 2011, em cujo texto explicita-se a seguinte referência: DAHMER, A. Disponível em: <http://malvados.wordpress.com>. Acesso em: 30 jun. 2011.

Trecho 1: Malditas câmeras, somos monitorados o tempo todo!

$\mathrm{O}$ encadeamento argumentativo que esse trecho permite evocar é [há câmeras em todo lugar, portanto ser monitorado o tempo todo], cujo aspecto expresso é HAVER CÂMERAS EM TODA PARTE DC SER SEMPRE MONITORADO, que constitui a AI de Sociedade do Controle. Observe-se, além disso, que a AI de malditas, nesse trecho, é constituída pelo aspecto argumentativo NEG-DEVERIA HAVER CÂMERAS PT HÁ.

Trecho 2: Se você está me ouvindo, saiba que podemos lutar contra a Sociedade do Controle juntos!

Da análise semântico-argumentativa dos enunciados desse segundo trecho do texto resultam dois aspectos argumentativos neles expressos: o primeiro, OUVIR DC SABER [QUE PODE LUTAR CONTRA O CONTROLE], constitui uma AI de cidadania, e o segundo, HÁ SOCIEDADE DO CONTROLE DC LUTAR
CONTRA O CONTROLE, constitui uma $\mathrm{AE}$ de Sociedade do Controle.

Trecho 3: Apenas linguagem não verbal

Observe-se que esse terceiro trecho, contendo apenas linguagem não verbal, permite evocar o encadeamento argumentativo transgressivo, [monitorar, mesmo assim ser monitorado], ao qual se pode associar o aspecto argumentativo, já relacionado no primeiro trecho, no qual se constitui a AI de Sociedade do Controle: HAVER CÂMERAS EM TODA PARTE DC SER SEMPRE MONITORADO.

Desse modo, verifica-se que esse terceiro quadrinho da tira tem a função de exemplificar, por meio de imagens, o funcionamento da Sociedade do Controle, explicitando que até mesmo quem monitora é monitorado. Portanto, de acordo com o que propôs (GRAEFF, 2012), pode-se dizer que esse trecho conecta-se aos anteriores pelo processo de similaridade, permitindo que fosse 
colocada, entre o segundo e o terceiro quadrinho, a expressão por exemplo. Nessa direção, o sentido desse terceiro quadrinho, contendo apenas linguagem não verbal, é garantido pela linguagem verbal - igualmente notado por Graeff e Gomes (2014), ${ }^{7}$ a propósito do estudo da relação entre linguagem verbal e não verbal em tiras pela semântica argumentativa.

Diante do exposto, é possível afirmar que a ideia central desse último texto que compõe a proposta de redação pode ser resumida no aspecto argumentativo HAVER CÂMERAS EM TODA PARTE DC SER MONITORADO, visto que explicita o próprio sentido de Sociedade do Controle.

Entretanto, é importante que se observe aqui o acréscimo de um novo tema à proposta de redação, uma vez que o tema Viver em rede no século XXI: os limites entre o público e o privado já está delimitado no âmbito da internet, mais especificamente das redes sociais. Logo, não pode ter relação direta com o tema Sociedade do Controle. Ambos poderiam se conectar, por exemplo, num assunto como Novas Tecnologias da Informação e da Comunicação. No entanto, a própria língua veta a possibilidade de se efetuar conexão por similaridade entre enunciados que relacionam esses dois temas num mesmo discurso, visto que as suas argumentações internas devem ser diferentes. Acredita-se, em razão disso, que os alunos poderiam apresentar dificuldade em relacionar e, sobretudo, em articular esse último texto aos dois anteriores, dentro dos padrões do texto dissertativo-argumentativo, sem tangenciar ou até mesmo fugir ao tema proposto.

Por fim, vale ainda destacar que a ideia central da proposta de redação do Enem 2011 pode ser resumida no aspecto argumentativo transgressivo TER LIBERDADE ILIMITADA DE INTERAÇÃO PT TER DE LIMITAR O QUE PUBLICA, cujo bloco semântico relaciona ter liberdade ilimitada de interação e ter de limitar que se publica em rede. Note-se que o primeiro segmento corresponde à ideia central do primeiro texto e todo o encadeamento corresponde à ideia central do segundo texto.

\section{Considerações finais}

Considerando que este trabalho se propôs apresentar procedimentos de leitura de propostas de redação do Enem, com base na semântica argumentativa, os procedimentos de análise a serem considerados nas situações de ensino de leitura e produção textual e/ou de avaliação, que se propuserem a utilizá-los, são estes: a) devem-se evocar os encadeamentos argumentativos em DC (portanto) e/ou em PT (mesmo assim) que resumem os textos; b) a cada encadeamento argumentativo evocado deve-se associar o aspecto argumentativo do bloco semântico nele expresso; c) deve-se encontrar o encadeamento argumentativo que constitui a ideia central de 
cada texto da proposta e, por último, d) o encadeamento que resume toda a proposta de redação, o qual corresponde à sua ideia central.

Relativamente à ideia central da proposta, observe-se que ela deverá coincidir com um encadeamento argumentativo em DC ou em PT, no caso de ser uma das duas unidades semânticas básicas, ou, no caso de ser uma estrutura complexa, com a articulação de encadeamentos em DC - caso do uso de mas de oposição indireta, como Pedro estudou, mas a prova foi muito difícil - ou com a articulação de um encadeamento em DC e outro em PT - caso de dois predicados ligados por mas também, como Eu defenderei os interesses dos que votaram em mim, mas também dos que votaram contra mim, conforme a descrição apresentada por Carel (2005).

Encontrada a ideia central da proposta de redação, podem-se definir os conceitos de entendimento, tangenciamento e fuga de tema, essenciais para a avaliação de desempenhos em leitura. No caso da proposta de redação do Enem analisada neste trabalho, entender o tema significa explicitar os dois predicados que constituem $o$ aspecto argumentativo da ideia central da proposta; tangenciar o tema significa explicitar, no texto, apenas um dos predicados dessa ideia central e fugir do tema significa não explicitar nenhum dos dois predicados que constituem a ideia central da proposta. Tendo-se os referidos conceitos bem estabelecidos, pode-se assegurar uma avaliação mais qualificada dos desempenhos do participante em leitura.

Em vista disso, saliente-se a produtividade de se levarem as ferramentas de análise linguístico-discursiva, postas à disposição pela semântica argumentativa, para o ensino de leitura na escola, visto que, como se apresentou neste trabalho, além de ser possível ensinar procedimentos de leitura de propostas de redação, o professor também conseguirá assegurar aos estudantes um tratamento mais justo na avaliação de seus desempenhos em leitura.

\section{Argumentative reading of Enem's composition proposal and criteria for defining escape and tangency of the theme}

\begin{abstract}
This work proposes an integrated reading of the texts that compose the Enem 2011's composition proposal, which explains the relationship between the central ideas of each text, to reach the central idea of the proposal. From this it is seeking to establish the limits of understanding, tangency and escape from the central idea of the composition proposal. This reading procedure uses principles and concepts of the Theory of the Semantic Blocks - current version of the theory of Argumentation Within Language - developed by Oswald Ducrot and Marion Carel at School for Advanced Studies in Social Sciences in Paris. The aim of this study provide theoretical and methodological subsidies capable of to qualify the teaching of reading practices and production
\end{abstract}


dissertative-argumentative texts, and the criteria used in the evaluation of reading performance.

Keywords: Reading. Composition proposal. Teaching. Semantic block.

\section{Notas}

1 Este trabalho foi desenvolvido na dissertação de mestrado de Lauro Gomes, intitulada Avaliação de leitura e produção de textos dissertativo- argumentativos pela Teoria da Argumentação na Língua, orientada por Telisa Furlanetto Graeff, defendida no PPGLetras da Universidade de Passo Fundo em 2014.

2 A afirmação de que a avaliação do desempenho do participante na leitura da proposta de redação envolve subjetividade baseia-se na abordagem cognitivista de Van Dijk (1992), segundo a qual a interpretação é um ato mental, um processo cognitivo dos usuários da linguagem, sendo, portanto, o seu resultado uma representação conceitual do discurso na memória.

3 Saliente-se que a objetividade, à qual se faz referência aqui, é uma objetividade que evita a discrepância. Reconhece-se a impossibilidade de se eliminar plenamente a subjetividade do examinador no processo de avaliação; crê-se, no entanto, que, atribuindo critérios linguísticos de avaliação de leitura e escrita, podem-se envolver menos as crenças pessoais do avaliador no processo de avaliação.

4 “[...] está constituida por un cierto número de aspectos a los que pertenecen los encadenamientos que parafrasean esta entidad $e . "$

5 "[...] un morceau de texte constitue un "motif argumentatif' si, à la fois, il exprime un aspect et évoque un enchaînement, c'est-à-dire s'il communique un jugement complet."

6 "Un hiver, l'ouvrage manqua. Pas de feu ni de pain dans le galetas. L'homme, la fille et l'enfant eurent froid et faim. L'homme vola. Je ne sais ce qu'il vola, je ne sais où il vola. Ce que je sais, c'est que de ce vol il résulta trois jours de pain et feu pour la femme et pour l'enfant, et cinq ans de prison pour l'homme."

7 Este trabalho, intitulado A relação semântica entre linguagem verbal e não verbal em tiras, com base na semântica argumentativa, de autoria de Telisa Furlanetto Graeff e Lauro Gomes, encontra-se, no prelo. GRAEFF, Telisa
Furlanetto; GOMES, Lauro. A relação semântica entre linguagem verbal e não verbal em tiras, com base na semântica argumentativa. Estudos da Língua(gem), Vitória da Conquista, v. 13 , n. 1, p. 47-62, 2015. ISSN 1808-1355-versão impressa. ISSN 1982-0334-versão online.

\section{Referências}

CAREL, Marion. Pourtant: argumentation by exception. Journal of Pragmatics, Philadelphia, v. 24, p. 167-188, 1995.

. O que é argumentar? Desenredo, Passo Fundo, v. 1, n. 2, p. 77-84, jul./dez. 2005.

Introduction. In: CAREL, M. (Org.).

Argumentation et polyphonie: de Saint Augustin à Robbe-Grillet. Paris: L'Harmattan, 2012. p. 7-58.

. Tu serás um homem, meu filho. Um prolongamento da doxa: o paradoxo. Desenredo, Passo Fundo, v. 9, n. 2, p. 254-270, jul./ dez. 2013.

CAREL, Marion; DUCROT, Oswald. La semántica argumentativa: una introducción a la teoría de los bloques semánticos. Tradução de María Marta Negroni e Alfredo M. Lescano. Buenos Aires: Colihue, 2005.

COSTA VAL, Maria da Graça. Redação e textualidade. 3. ed. São Paulo: Martins Fontes, 2006.

DUCROT, Oswald. Polifonía y argumentación. Conferencias del Seminario Teoría de la Argumentación y Análisis del Discurso. Cali: Universidad del Valle, 1990.

A conexão entre os enunciados no texto com base na semântica argumentativa. Desenredo, Passo Fundo, v. 8, n. 2, p. 197-208, jul./dez, 2012.

GRAEFF, Telisa Furlanetto; GOMES, Lauro. De prática discursiva a um novo gênero: proposta de redação. In: SEMINÁRIO NACIONAL DE LÍNGUAE LITERATURA: TEORIA E PRÁTICA - DIÁLOGOS EM DISCURSOS, 4., 2012, Passo Fundo. Anais..., Passo Fundo: UPF Editora, 2012. p. 1-10. 
INEP. Instituto Nacional de Estudos e Pesquisas Educacionais Anísio Teixeira. Exame Nacional do Ensino Médio (Enem). A redação no Enem 2013: guia do participante. Brasília: Inep/MEC, 2013.

VAN DIJK, Teun A. Cognição, discurso e interação. São Paulo: Contexto, 1992. (Organização e apresentação de Ingedore V. Koch). 